\title{
Severe Gram-Negative Intertrigo of the Feet
}

\author{
Luisa Angileri ${ }^{*}$, Stefano Veraldi ${ }^{1}$
}

${ }^{1}$ Department of Pathophysiology and Transplantation, Dermatology Unit, University of Milan, I.R.C.C.S. Foundation, Cà Granda Ospedale Maggiore Policlinico, Milan, Italy

Corresponding Author: Luisa Angileri, MD, Postgraduate School of Dermatology and Venereology, University of Milan, Via Pace 9, 20122 Milan, Italy. Tel: +39-0255035107, Email: luisaangileri@ hotmail.it

Received August 11, 2017; Accepted November 9, 2017; Online Published November 26, 2017

\begin{abstract}
Introduction: Intertrigo is a common disease of the skin usually caused by fungi and/or bacteria, often involving major or minor skin folds. Here, we report a case of severe, ulcerative intertrigo of all interdigital folds of both feet caused by Pseudomonas aeruginosa in a patient with type II diabetes who acquired the infection during a trip to Senegal.

Case Presentation: Lesions involved all toe-web spaces and the back of the toes and the soles. Ulcers with a purulent-necrotic bed, with some of them covered by brownish-black eschars associated with a greenish, odiferous discharge were recorded. The patient was treated with piperacillin/tazobactam IM for 14 days, achieving complete remission of the infection. In this article, we underline the importance of an early diagnosis and appropriate treatment to achieve healing of bacterial intertrigo without complications. Topical therapy with antiseptics (potassium permanganate, gentian violet solution, hydrogen peroxide) or antibiotics (gentamicin, amikacin) is effective only in early stages of the infection. Systemic antibiotics must be considered in all extensive and severe cases. The choice of antibiotic should be based on the culture and antibiogram results. When this is not possible, wide-spectrum antibiotics that act on both gram-positive and gram-negative bacteria (such as third-generation cephalosporin or quinolone) should be prescribed.

Conclusion: The length of treatment should not be less than ten days. In addiction, all patients should be trained to avoid predisposing conditions and adopt preventive measures to reduce the risk of infection.

Keywords: Intertrigo, Pseudomonas aeruginosa, Gram-Negative Infection
\end{abstract}

\section{Introduction}

Intertrigo is a common disease of the skin, usually caused by fungi and/or bacteria. Major folds, such as the submammary, abdominal and inguinal, are often involved. Intertrigo of the interdigital folds of the feet can also occur. This type can be caused by dermatophytes (interdigital tinea pedis), yeast (mainly Candida albicans) or gram-negative bacteria. ${ }^{1-3}$ The case reported herein is severe, ulcerative intertrigo of all interdigital folds of both feet caused by Pseudomonas aeruginosa in a patient with type II diabetes who acquired the infection during a trip to Senegal.

\section{Case Presentation}

A 79-year-old Caucasian male was admitted to the Dermatology Unit because of the acute appearance of ulcers located in all interdigital folds of both feet and soles. The patient complained of severe pain which made walking very difficult. The patient was afflicted by type II diabetes, essential arterial hypertension and chronic gastritis, for which he was being treated with metformin, nebivolol, olmesartan, furosemide, spironolactone, clopidogrel and pantoprazole. The patient stated that the lesions appeared during a trip to Senegal, where he had walked barefoot several times, at the toe web spaces and, within a few days, involved the back of the toes and the soles.

Dermatological examination revealed ulcers of different morphology and size with purulent-necrotic beds, some of which were covered by brownish-black eschars. A greenish, odiferous discharge was present (Figure 1). General physical examination did not reveal a pathology; in particular, no inguinal lymphadenopathy was recorded. Laboratory examinations revealed only a mild decrease in erythrocytes, the hemoglobin and hematocrit and an increase in monocytes. All the other laboratory tests, including inflammatory values, were within normal ranges or negative.

A diagnosis of gram-negative intertrigo was made. The cultures were positive for $P$. aeruginosa, that was shown to be sensitive to piperacillin/tazobactam. Mycological

Copyright $(\odot 2018$ The Author(s). This is an open-access article distributed under the terms of the Creative Commons Attribution License (http:// creativecommons.org/licenses/by/4.0), which permits unrestricted use, distribution, and reproduction in any medium, provided the original work is properly cited. 


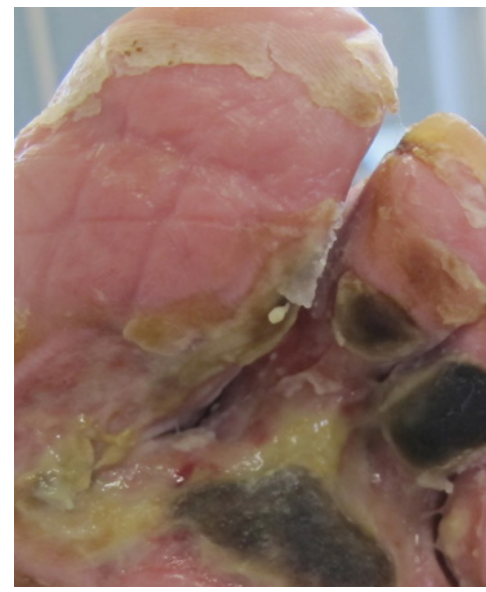

Figure 1. Ulcers with a Purulent-Necrotic Bed, Brownish-Black Eschars and a Greenish, Odoriferous Discharge.

examinations were negative. The patient was treated with piperacillin/tazobactam IM (2/0.25 g/d for 14 days). Complete remission of the infection was observed by the end of treatment. The follow-up (13 months) was negative.

\section{Discussion}

Intertrigo of the feet was first described by Amonette and Rosenburg in 1973. ${ }^{1}$ It occurs mainly in adult males. Diabetes, obesity, long-term therapy with antibiotics, corticosteroids or immunosuppressants and previous or concomitant dermatitis (irritant or allergic contact dermatitis, tinea pedis) are considered to be risk factors. With regard to tinea pedis, it has been demonstrated that a previous mycotic infection can promote a subsequent gram-negative bacteria infection. Dermatophytes and yeast can damage the stratum corneum, inducing maceration and scaling. ${ }^{2}$ In addition, inadequate footwear can induce occlusion and maceration of interdigital folds $s^{3}$ and high temperature and humidity stimulate gramnegative bacteria proliferation. ${ }^{4,5}$ Local flora of the feet contains several gram-negative bacteria that are often isolated in intertrigo of the feet. ${ }^{6,7}$

Intertrigo of the feet is caused by multiple pathogens in approximately $73 \%$ of cases. ${ }^{8}$ P. aeruginosa often combines with other gram-negative bacteria, such as Enterobacter spp., Escherichia coli, Klebsiella pneumoniae, Proteus mirabilis, Moraxella spp., Acinetobacter spp. and Erwinia spp. ${ }^{9}$ The presence of $P$. aeruginosa can be suspected in the presence of a greenish exudate and the odor of grapefruit. ${ }^{10} P$. aeruginosa produces multiple hydrosoluble pigments, such as pyocyanin, a greenish-blue, non-fluorescent pigment responsible for the characteristic green discoloration of the exudate, and pyoverdin, a greenish-yellow pigment which fluoresces under a Wood light. Trimethylamine is responsible for the typical sweet, grapefruit-like odor. ${ }^{11}$ Gram-positive infections are usually caused by Staphylococcus aureus and other coagulasenegative staphylococci. Sometimes gram-negative and grampositive bacteria occur simultaneously.,12

The third and fourth toe web spaces are more commonly involved, although all toe web spaces can be involved. Intertrigo can extend to the back of the toes and the sole and the back of the feet can also be involved. Intertrigo causes a burning sensation and pain and, in untreated or severe cases, patients will have difficulty walking, as in our patient.

Treatment of intertrigo is not easy. In our experience, topical treatment with antiseptics (potassium permanganate, gentian violet solution, hydrogen peroxide) or antibiotics (gentamicin, amikacin) is effective only in the early stages of the infection and when it is limited to a single interdigital fold. In some cases, gentle debridement may be necessary in order to remove pus and necrotic tissue and allow the application of topical agents. Systemic antibiotics must be considered in all other cases.

The choice of antibiotic should be based on the culture and antibiogram results. When an antibiogram is not available, it is possible to prescribe wide-spectrum antibiotics that act on both the gram-positive and gram-negative bacteria, such as third-generation cephalosporin or quinolone. Cefotaxime, ceftazidime, ceftriaxone and ciprofloxacin are usually effective; however, the length of treatment should not be less than ten days. All patients should be trained to avoid local predisposing conditions and adopt preventive measures. These include good hygiene, keeping the toe webs dry, use of absorbent clothing, avoidance of occlusive footwear and frequent water-related activity, avoidance of nylon and other synthetic fibers. ${ }^{13}$

\section{Conclusion}

In conclusion, early diagnosis and appropriate treatment are essential to achieve healing of bacterial intertrigo without complications. Major emphasis should be made on adoption of preventive measures, especially in patients with type I diabetes.

\section{Authors' Contributions}

LA and SV contributed equally to this study.

\section{Conflict of Interest Disclosures}

The authors declare that there is no conflict of interest.

\section{Ethical Approval}

Informed consent was obtained from the patient for publication as a case report.

\section{Funding/Support}

None.

\section{References}

1. Amonette RA, Rosenberg EW. Infection of toe webs by gram-negative bacteria. Arch Dermatol. 1973;107(1):71-73. doi:10.1001/archderm.1973.01620160043012.

2. Leyden JJ. Progression of interdigital infections from simplex to complex. J Am Acad Dermatol. 1993;28(5 Pt 1):S7-S11. doi:10.1016/S0190-9622(09)80301-0.

3. Westmoreland TA, Ross EV, Yeager JK. Pseudomonas toe web infections. Cutis. 1992;49(3):185-186.

4. Leyden JJ, Stewart R, Kligman AM. Experimental inoculation of Pseudomonas aeruginosa and Pseudomonas cepacia on human skin. J Soc Cosmetic Chemists. 1980;31:19-28.

5. Hojyo-Tomoka MT, Marples RR, Kligman AM. Pseudomonas infection in superhydrated skin. Arch Dermatol. 1973;107(5):723- 
727. doi:10.1001/archderm.1973.01620200041010.

6. Noble WC, Hope YM, Midgley G, et al. Toewebs as a source of gram-negative bacilli. J Hosp Infect. 1986;8(3):248-256. doi:10.1016/0195-6701(86)90120-9.

7. Aly R, Maibach HI. Aerobic microbial flora of intertrigenous skin. Appl Environ Microbiol. 1977;33(1):97-100.

8. Eaglstein NF, Marley WM, Marley NF, Rosenberg EW, Hernandez AD. Gram-negative bacterial toe web infection: successful treatment with a new third generation cephalosporin. J Am Acad Dermatol. 1983;8(2):225-228. doi:10.1016/S01909622(83)70028-9.

9. Aste N, Atzori L, Zucca M, Pau M, Biggio P. Gram-negative bacterial toe web infection: a survey of 123 cases from the district of Cagliari, Italy. J Am Acad Dermatol. 2001;45(4):537-541. doi:10.1067/mjd.2001.114747.
10. Ward CG, Clarkson JG, Taplin D, Polk HC Jr. Wood's light fluorescence and Pseudomonas burn wound infection. JAMA. 1967;202(11):1039-1040. doi:10.1001/ jama.1967.03130240081015.

11. Silvestre JF, Betlloch Ml. Cutaneous manifestations due to Pseudomonas infection. Int J Dermatol. 1999;38(6):419-431. doi:10.1046/j.1365-4362.1999.00606.x.

12. Janniger CK, Schwartz RA, Szepietowski JC, Reich A. Intertrigo and common secondary skin infections. Am Fam Physician. 2005;72(5):833-838.

13. Mistiaen P, Poot E, Hickox S, Jochems C, Wagner C. Preventing and treating intertrigo in the large skin folds of adults: a literature overview. Dermatol Nurs. 2004;16(1):43-46. 